\title{
The usual suspects: do risk tolerance, altruism, and health predict the response to COVID-19?
}

\author{
Ketki Sheth ${ }^{1} \cdot$ Greg C. Wright ${ }^{1}$
}

Received: 15 June 2020 / Accepted: 6 October 2020 / Published online: 24 October 2020

(c) Springer Science+Business Media, LLC, part of Springer Nature 2020

\begin{abstract}
We survey college students during California's stay-at-home order to test whether compliance with social distancing requirements depends on primary preferences and characteristics that affect their marginal benefit from doing so. We find a quarter of students violated the order. Yet, neither risk preference, altruism, nor preexisting health conditions were predictive of compliance. Our findings raise doubt about the efficiency of minimally enforced social distancing policies, as well as commonly assumed motivations for compliance. Our results also imply that those with preexisting health conditions may not voluntarily comply, resulting in higher health care congestion than otherwise expected.
\end{abstract}

Keywords COVID-19 $\cdot$ Risk $\cdot$ Altruism $\cdot$ Health

\section{Introduction}

In response to the COVID-19 pandemic, Americans are being encouraged - and in many states ordered - to socially distance and stay at home. ${ }^{1,2}$ Yet, there are concerns that many people have failed to comply and there has been pressure to relax requirements, both of which have important efficiency implications for these policies. $^{3}$ This raises two key questions: to what extent are people not complying with orders to reduce social interaction? And what drives this non-compliance?

\section{Greg C. Wright}

gwright4@ucmerced.edu

1 University of California, Merced, CA, USA

\footnotetext{
${ }^{1}$ Since March 2020, 45 states have issued statewide orders to stay at home.

${ }^{2}$ Social distancing is broadly defined as staying six feet away from others. Stay-at-home is generally a legal order for people to stay in their home, except for essential activities such as food, health care, and employment.

${ }^{3}$ E.g., Murdoch (2020) and Behrmann (2020).
} 
Given the policy's dual mandate to protect individuals from harm and reduce the transmission to others, this paper examines whether primary preferences and characteristics that align with these objectives are predictive of compliance. Specifically, whether preexisting health factors, risk aversion, and altruism predict staying at home and socially distancing. If individuals respond to the policy based on their own benefits from compliance, we should expect that those who are at greater risk of severe consequences from an infection, or more risk averse, will be more likely to comply. Likewise, those who are more altruistic should also have higher compliance because this reduces the likelihood of infecting others.

Exploiting multiple surveys of California undergraduate students during a stay-athome order, ${ }^{4}$ we find that a quarter of our subjects violated the order for non-essential reasons. Yet neither preexisting health factors, risk aversion, nor altruism predicted compliance with social distancing guidelines. This is despite the fact that both existing health conditions and risk aversion have been shown to increase preventative health behaviors, and altruism has been shown to affect similar decisions in the context of communicable diseases (Anderson and Mellor 2008; Hurley and Mentzakis 2013; Schmitz and Wubker 2010). We did find that more risk tolerant individuals were more likely to leave their homes and not socially distance when obtaining essential services or for employment (i.e., behaviors that were permitted under the order). Yet, when these exceptions are excluded, we no longer found that risk tolerance was predictive of compliance.

Current stay-at-home orders are minimally enforced, such that individuals mostly self-select into compliance. This may be efficiency enhancing when compliance is determined by underlying preferences or health conditions that individuals face. In contrast, if an individual's decision-making is driven by misperceptions of their true benefits and costs, then self-enforcement will reduce welfare (Allcott et al. 2020; Barrios and Hochberg 2020). Our findings support the latter, as variation in compliance does not reflect differences in underlying preferences or primary conditions that affect illness severity.

Our findings also inform research on the optimal public policy response to the pandemic, which has generally assumed that compliance with social distancing should increase with the severity of the health risk faced by an individual (Chudik et al. 2020; Glover et al. 2020; Rampini 2020). Our results highlight that this may not be true for policies that rely on self-selection into preventative behaviors. ${ }^{5}$ Since hospitalization rates are higher among these vulnerable individuals, a consequence is that minimal enforcement may result in greater health care congestion than is assumed in current policy analyses.

Beyond academic research, public commentary on the pandemic has made similar assumptions. Contrary to our findings, many assume that preferences and

\footnotetext{
${ }^{4}$ California's Stay-at-Home measure (Executive Order N-60-20, implemented March 19, 2020) allowed individuals to leave their home for "permitted work" or to obtain essential services (i.e., "necessities as food, prescriptions, and health care") during the period of our study. Permitted work included jobs in 16 critical infrastructure sectors, and only essential services such as grocery stores, takeout and delivery restaurants, health care services, pharmacies, and banks remained open (Tan and Bhattacharjee 2020).
}

5 This is similar to lack of selective recruitment found in seat-belt adoption among youth (Cohen and Einav 2003). 
health risks drive the response to stay-at-home orders. Those who violate social distancing guidelines are accused of being less altruistic (i.e., selfish) (BBC 2020). Likewise, those who argue against the orders claim that risk aversion (i.e., cowardice) is resulting in an overreaction to the pandemic, and that those with greater health risks will naturally continue to socially distance even if restrictions were relaxed (Emerson and DeSilvia 2020; Williams 2020). Our results suggest that these inferences may be misguided, undermining productive debate on the public policy response to the pandemic.

Our findings also suggest that highlighting personal risk and reduced transmission to others may be ineffective at improving compliance, at least at this stage of the pandemic. And that as social distancing requirements continue, compliance is unlikely to alter the composition of the voting electorate to be more risk-loving, less altruistic, or healthier.

These findings contribute to the literature identifying how demographics and risk perceptions affect the response to health policy during a pandemic (Bish and Michie 2010; Bults et al. 2011; Ibuka et al. 2010). In the context of COVID-19, Wise et al. (2020) find that perceived personal risk is associated with preventative behaviors, but that people are poor at assessing their actual risk. In contrast to our findings, Campos-Mercade et al. (2020) find that in Sweden prosocial preferences are predictive of adopting preventative behaviors, including physical distancing. ${ }^{6}$ The difference may be explained by the fact that their sample includes adults of all ages and educational achievement, whereas we focus on college students. In addition, the Swedish policy response differed significantly from stay-at-home orders in the United States, and more explicitly relied on individual discretion to socially distance; for example, restaurants, malls, and gyms remained open in Sweden. Finally, responsiveness to the pandemic may have been more politicized in the United States, dampening responsiveness to primary preferences and characteristics. Indeed, risk perception of COVID-19 and social distancing has been shown to be affected by partisan leanings in the United States (Allcott et al. 2020; Barrios and Hochberg 2020). Also in the context of COVID-19, our findings are generally consistent with the literature that cautions that the decision to socially distance may not reflect one's true marginal benefit from doing so.

We also contribute to the broader literature explaining individual health care decisions. Our focus on risk tolerance, altruism, and health conditions is guided by a literature that explores these factors in the adoption of preventative health behaviors (Anderson and Mellor 2008; Hurley and Mentzakis 2013; Schmitz and Wubker 2010), and the much larger literature that explores risk and altruism preferences in decision making (e.g., Kolm and Ythier 2006). We also contribute to the literature exploring altruism in decision-making when externalities are present (Fischbacher and Gachter 2010; Frey and Meier 2004; Korinek and Bethune 2020).

\footnotetext{
${ }^{6}$ Campos-Mercade et al. (2020) include the same measures of altruism that we use, confirming that the different findings are not a reflection of how altruism is measured.
} 


\section{Research design and data}

We administer two survey instruments to 338 undergraduate economics students at a large California university between March 26th and April 7th, 2020, 6 days after California's stay-at-home order went into effect. ${ }^{7}$

Both surveys asked about compliance with the order in the previous $24 \mathrm{~h}$ : (1) whether subjects left their home (Left Home), and (2) whether subjects were within six feet of another person, excluding people living in their home, for purposes other than obtaining food, health care, or banking services (Socialized). In the second survey instrument, we additionally ask whether an affirmative to the latter question occurred outside the context of paid employment (Socialized, Not Work). We observe two to six responses per subject, as a subset of subjects were recruited to complete the surveys more than once.

In the first survey instrument, subjects were also asked standard questions eliciting altruism preferences. ${ }^{8}$ In the second survey instrument, we collect information on the subjects' demographic characteristics (e.g., gender, age), characteristics that increase the risk of severity from a COVID-19 infection (i.e., whether they or someone they are living suffer from conditions that make them a high-risk population for COVID$19)$, risk preference, and beliefs on the effectiveness of social distancing and consequences of COVID-19.

We elicit risk and altruism preferences using standard self-reported measures that have been validated across various populations (and countries), and have been shown to be predictive of risky behaviors (e.g., smoking, holding stocks) and altruistic behaviors (e.g., helping strangers, volunteering), respectively (Dohmen et al. 2011; Falk et al. 2016, 2018a). Risk preference is measured by an 11-point scale, in which subjects were asked "how willing or unwilling are you to take risks, using a scale from 0 to 10" that increased in the willingness to take risks. Following Falk et al. (2016), altruism is measured using a weighted average of two normalized measures, increasing with altruism. The first question asks about a donation amount: "Today you unexpectedly received 1,600 USD. How much of this amount would you donate to a good cause?" The second question asks subjects "how willing are you to give to good causes without expecting anything in return?," using a scale from 0 to 10 that increases in the willingness to give. To create the altruism measure, we normalize each underlying measure and create a weighted composite for each survey response.

Subjects were also asked whether they, or those they were living with, have characteristics that increase their likelihood for more severe illness from

\footnotetext{
7 We recruited 525 subjects by inviting enrolled students in seven undergraduate economic courses. Three hundred and thirty-eight subjects, our main sample, completed both survey instruments. We confirm our results are robust to the inclusion of 59 additional subjects that completed only one survey instrument. Multiple responses from a subject is due to our recruitment method and reflect the subject's enrollment in multiple recruited courses.

${ }^{8}$ In addition, at the end of the first survey, a subset of subjects were given information on the benefits of social distancing using random assignment. We randomly assigned subjects to receive no additional information, a $15 \mathrm{~min}$ lecture on the reduced personal risks from social distancing, or a $15 \mathrm{~min}$ lecture on the benefits to others from social distancing. We do not find support for this variation in information treatment having changed social distancing behavior. The Online Appendix provides additional detail on the timing of when key variables were elicited and the randomized information intervention.
} 
COVID-19. Specifically, we use the characteristics reported by the Centers for Disease Control (CDC) to identify what conditions increase the potential severity of a COVID-19 infection. The CDC (2020b) reports that based on current information (at the time), people with the following factors are at higher risk for severe illness from COVID-19: (1) 65 years and older, (2) chronic lung disease, (3) moderate to severe asthma, (4) immunocompromised, (5) severe obesity (body mass index above 40), (6) diabetes, (7) chronic kidney disease undergoing dialysis, and (8) liver disease. We inquire about each of these conditions separately, and then create a composite indicator variable. Our main variable, High Risk, is an indicator for having any of these factors, but results are similar when considering each condition separately.

The second survey instrument was implemented a few days after the first survey instrument. We therefore assume that these characteristics, asked in only one survey instrument, are time-invariant for our primary analysis. ${ }^{9} \mathrm{We}$ similarly assume additional covariates used as control variables are time-invariant. Subjects were informed that their responses would be anonymous. Subjects in multiple recruited courses were invited to complete a survey more than once. We therefore calculate subject means across all their surveys in our primary analysis. The Appendix provides additional details, including construction and validation, of all variables.

\subsection{Additional measures used as controls}

The following measures were questions asked in the second survey instrument.

Subjects were asked whether they, or anyone they are currently living with, experienced symptoms of COVID-19 over the previous 7 days (i.e., fever, cough, shortness of breath). This variable is referred to as Covid19 Symptom.

Using Likert questions (on a scale of 1 to 5), we ask subjects about their opinion on (1) how serious a COVID-19 infection is for younger, healthy adults (Serious), (2) how effective social distancing is at slowing down the spread of COVID-19 (Health Effective), and (3) how effective is social distancing at improving the economic impact from COVID-19 (Econ Effective). We also ask subjects to predict the unemployment rate in June 2020 (Unemployment).

Finally, we ask subjects a series of questions about COVID-19 that were based on the information provided to a random subset of students in the initial survey. We ask subjects whether misperceptions of low personal risk and externalities would result in a less-than-efficient adoption of social distancing (Low SD, Misperception and Low $S D$, Externalities). We ask them the hospitalization rate of younger adults infected with COVID-19 in the United States (Hosp. Rate), and the number of people that would become infected after ten social links, if each person infects three others (Potential Spread). These latter two questions provided four multiple choice options.

\subsection{Sample description}

Table 1 reports summary statistics for our analysis sample. Fifty-four percent of the sample is male and the majority of our sample is aged 19 to 21 (reflecting their

\footnotetext{
${ }^{9}$ Our results are robust to relaxing this assumption.
} 
Table 1 Summary statistics

\begin{tabular}{|c|c|c|c|c|}
\hline & Mean & SD & Min & Max \\
\hline Male & 0.54 & 0.50 & 0.00 & 1.00 \\
\hline Age 19 & 0.20 & 0.40 & 0.00 & 1.00 \\
\hline Age 20 & 0.27 & 0.45 & 0.00 & 1.00 \\
\hline Age 21 & 0.27 & 0.44 & 0.00 & 1.00 \\
\hline Age above 21 & 0.17 & 0.38 & 0.00 & 1.00 \\
\hline Covid19 Symptom & 0.26 & 0.43 & 0.00 & 1.00 \\
\hline Risk Tolerant & 4.96 & 2.72 & 0.00 & 10.00 \\
\hline Altruism Donation & 271.20 & 385.62 & 0.00 & 1600.00 \\
\hline Altruism Scale & 7.14 & 2.77 & 0.00 & 10.00 \\
\hline High Risk & 0.38 & 0.48 & 0.00 & 1.00 \\
\hline Serious & 2.59 & 1.03 & 1.00 & 5.00 \\
\hline Health Effective & 1.89 & 0.89 & 1.00 & 5.00 \\
\hline Econ Effective & 2.83 & 1.36 & 1.00 & 5.00 \\
\hline Unemployment & 32.15 & 20.52 & 2.48 & 100.00 \\
\hline Low SD, Misperception & 0.28 & 0.23 & 0.00 & 0.50 \\
\hline Low SD, Externalities & 0.31 & 0.22 & 0.00 & 0.50 \\
\hline Hosp. Rate & 1.77 & 0.82 & 1.00 & 4.00 \\
\hline Potential Spread & 3.09 & 1.09 & 1.00 & 4.00 \\
\hline Observations & 333 & & & \\
\hline
\end{tabular}

Observations are individual subjects in our primary analysis. If subjects completed multiple responses, we provide the mean over all surveys for the subject. Male and Age variables are indicators of the given characteristic. COVID-19 Symptom is an indicator variable for whether the subject, or anyone with which they are living with, experienced shortness of breathe, cough, or fever in the previous 7 days. Risk Tolerant is a self-reported preference of risk on an 11point scale, increasing in risk tolerance. Altruism Donation is the amount of an unexpected US\$1600 that one would donate to a good cause, and is an underlying measure in our main altruism measure. Altruism Scale is a self-reported preference of the willingness to give on an 11-point scale, increasing in altruism, and is an underlying measure in our main altruism measure. High Risk is an indicator for whether the subject, or anyone they are living with, has a characteristic associated with increased likelihood of severe illness from COVID-19. Serious, Health Effective, and Econ Effective are five-point scales that reduce in the belief of how serious a COVID-19 infection is for younger healthy adults, how effective social distancing is at reducing the spread of the virus, and how effective social distancing is at reducing the economic impact from the virus, respectively. Unemployment is the expected unemployment rate in June 2020. Low SD, Misperceptions, Low SD, Externalities, Hosp. Rate, and Potential Spread are responses to questions that are based on factual information provided in initial surveys, as described in the Online Appendix.

undergraduate status). We do not ask additional demographic questions in our survey instruments, but the undergraduate population at the university is $61 \%$ underrepresented minorities, 74\% first generation college, and 64\% Pell Grant recipients. In general, underrepresented minorities may be more vulnerable to more severe illness from COVID-19 (CDC 2020a). 
We find that in $26 \%$ of the 7 day recall period, subjects reported experiencing, or living with someone experiencing, at least one symptom associated with COVID-19 (i.e., fever, cough, and shortness of breath). The mean reported risk preference is 4.96. Subjects self-reported an altruism measure of 7.14, and on average were willing to donate US\$271 to a hypothetical good cause (from an unexpected US\$1600 received). ${ }^{10}$ Using a Likert scale from 1 to 5 , subjects report a mean of 2.59 of the seriousness of a COVID-19 infection in younger healthy adults, a mean of 1.89 of the effectiveness of social distancing at slowing the spread of COVID-19, and a mean of 2.83 of the effectiveness of social distancing at improving the economic impact from COVID-19. The Likert scales are declining in seriousness and effectiveness, respectively. The mean estimate for the unemployment rate in June was $32 \%$.

Hosp. Rate reports subjects' estimates of the current hospitalization rate for younger COVID-19 patients (on a scale of 1 to 4, increasing in the hospitalization rate). Similarly, Potential Spread reports subjects' estimates of the transmission of the virus through a social network by an infected person (on a scale of 1 to 4, increasing in the number of others affected). Both these questions did have a correct answer, which was provided to some students in their initial survey, and so may reflect attentiveness or academic inclination. The former's correct range corresponded to 2, and the latter's correct range corresponded to 4. Similarly, Low SD, Misperceptions and Low SD, Externalities reflect correct responses regarding the fact that mis-perception of low personal risk and positive externalities will result in inefficiently low levels of socially distancing.

\subsection{Estimation methodology}

Using ordinary least squares, we estimate whether the primary preferences and characteristics theoretically associated with adoption of preventative measures predicts our key measures of compliance with the stay-at-home order:

$$
\overline{\text { Compliance }_{i}}=\alpha+\beta_{1} * \overline{\text { RiskTolerant }_{i}}+\beta_{2} * \overline{\text { Altruism }_{i}}+\beta_{3} \overline{\text { HighRisk }_{i}}+\overline{\mathbf{X}_{\mathbf{i}}}+\epsilon_{i}
$$

where Compliance refers to the indicators Left Home, Socialized, and Socialized, Not Work for individual i. $\boldsymbol{X}$ includes all covariates listed in Table 1 except Hosp. Rate and Potential Spread. ${ }^{11}$ For each variable, we use each subject's average response over all relevant surveys. For the compliance measures, each subject has a minimum of two responses and a maximum of six responses. We use student level means to confirm that each student is equally weighted in our analysis, and employ robust standard errors. $^{12}$

\footnotetext{
10 The main altruism measure used in the analysis is a weighted measure of these two altruism measures normalized into a z-score.

11 We exclude these two variables because these questions were not answered by nine subjects. Results are robust to including them in our main specification.

12 The minimum detectable effect for a simple linear regression model of $\alpha=0.05$, power $=0.80$, and sample size 333 is 0.1540 standard deviations. Including additional relevant regressors further reduces the minimum detectable effect.
} 
This specification and analysis is motivated by a preanalysis plan for the randomized information intervention delivered to a subset of students. In that preanalysis plan, we prespecify estimating heterogeneous effects by these three independent variables, based on their alignment with the motivations of compliance with stay-athome orders. We further prespecified how risk tolerance and altruism would be elicited and measured.

We implement several different specifications to confirm the robustness of our results. First, we modify specification (1) to exclude $\boldsymbol{X}$, confirming that characteristics that are correlated with preferences are not affecting our interpretation. Second, we expand the sample to include subjects that only completed one survey instrument. Because the key independent variables and covariates are measured in only one survey instrument, subjects that only completed one survey instrument will be missing some measures. We therefore estimate specification (1) for each independent variable separately and without covariates for this second robustness analysis. Finally, we relax the assumption that variables are time-invariant. We do so by using only observations in which both the outcome behavior (i.e., compliance) and the characteristic (i.e., risk preference) were asked in the same survey instrument. For example, we use a student's second survey response to explore if risk preference, which was asked in the second survey only, predicted behaviors. Because measures are asked in only one survey instrument, we again estimate these robustness specifications with each independent variable separately and without additional covariates.

\section{Results}

Though many subjects are in compliance with California's stay-at-home order, we find a large minority are not. Strikingly, 9 days after the order was issued and while over 1000 new cases were being reported daily in California, 25\% of subjects violated the stay-at-home order and socially interacted with others for non-essential, non-work purposes. Even more continued to leave their homes and socially interact, violating recommendations that accompany the order. Over the previous $24 \mathrm{~h}$, we find the rate of leaving home was $51 \%$, and the rate of socially interacting (for purposes other than food, health care, and banking services) was 35\%. This corresponds to $70 \%$ of subjects leaving their home and $50 \%$ socially interacting for at least one $24 \mathrm{~h}$ recall period. When limiting observations to the second survey instrument, which occurs further into the stay-at-home order, we continued to find significant non-compliance: $52 \%$ left home and $33 \%$ were in social proximity to others, only 8 percentage points of which was due to paid employment.

Table 2 follows specification (1) and regresses our primary measures of violating stay-at-home orders on risk tolerance, altruism, and the health factors associated with increased severity of COVID-19 (i.e., High Risk).

We find that those with higher risk tolerance are both more likely to leave their home and to interact socially. But surprisingly, when focusing on social interactions unrelated to obtaining essential services or paid employment, risk tolerance is not associated with non-compliance. This suggests that one's risk preference may affect the decision to engage in activities that are allowed under the order (e.g., obtaining food or employment). But when it comes to engaging in social interactions not 
Table 2 Predicting non-compliance

\begin{tabular}{|c|c|c|c|c|c|c|}
\hline \multirow{2}{*}{$\begin{array}{l}\text { Dependent } \\
\text { variable }\end{array}$} & \multicolumn{2}{|l|}{ Left Home } & \multicolumn{2}{|l|}{ Socialized } & \multicolumn{2}{|c|}{ Socialized, Not Work } \\
\hline & (1) & (2) & (3) & (4) & (5) & (6) \\
\hline Risk Tolerant & $\begin{array}{l}0.0439 * * * \\
(0.00730)\end{array}$ & $\begin{array}{l}0.0392 * * * \\
(0.00777)\end{array}$ & $\begin{array}{l}0.0134 * \\
(0.00814)\end{array}$ & $\begin{array}{l}0.0145^{*} \\
(0.00846)\end{array}$ & $\begin{array}{l}0.00643 \\
(0.00805)\end{array}$ & $\begin{array}{l}0.00988 \\
(0.00855)\end{array}$ \\
\hline Altruism & $\begin{array}{l}0.00787 \\
(0.0236)\end{array}$ & $\begin{array}{l}0.0279 \\
(0.0245)\end{array}$ & $\begin{array}{l}0.0197 \\
(0.0245)\end{array}$ & $\begin{array}{l}0.0155 \\
(0.0245)\end{array}$ & $\begin{array}{l}0.0147 \\
(0.0236)\end{array}$ & $\begin{array}{l}0.00490 \\
(0.0242)\end{array}$ \\
\hline High Risk & $\begin{array}{l}0.0371 \\
(0.0437)\end{array}$ & $\begin{array}{l}0.0391 \\
(0.0447)\end{array}$ & $\begin{array}{l}0.0453 \\
(0.0463)\end{array}$ & $\begin{array}{l}0.0306 \\
(0.0465)\end{array}$ & $\begin{array}{l}0.0607 \\
(0.0482)\end{array}$ & $\begin{array}{l}0.0550 \\
(0.0480)\end{array}$ \\
\hline Observations & 333 & 333 & 333 & 333 & 333 & 333 \\
\hline Controls & No & Yes & No & Yes & No & Yes \\
\hline Mean Dep. Var & 0.51 & 0.51 & 0.35 & 0.35 & 0.23 & 0.23 \\
\hline
\end{tabular}

Observations are individuals that completed both survey instruments at least once. Subject means across all surveys are used for independent and dependent variables. Using a $24 \mathrm{~h}$ recall period, Left Home is an indicator that the subject left home, Socialized is an indicator that the subject socially interacted within six feet of people not living with them and not for the purposes of food, health care, or banking services; Socialized, Not Work additionally excludes social interaction for paid employment purposes. Risk Tolerant ranges from 0 to 11 and is increasing in risk tolerance, Altruism ranges from -1.94 to 1.94 and is increasing in altruism, and High Risk is an indicator for whether the subject, or anyone they are living with, has a factor that increases the risk of a severe illness from a COVID-19 infection. Controls include all covariates listed in Table 1, except for Hosp. Rate and Potential Spread. Robust standard errors are in parentheses

$* p<0.10 ; * * p<0.05 ; * * * p<0.01$

sanctioned by the order risk preference is no longer a deciding factor. Indeed, for these latter two columns the upper bound in the $95 \%$ confidence interval of our point estimate is 2.7 (i.e., a one unit increase in reported risk tolerance is associated with a 2.7 percentage point increase in the probability of socializing for purposes outside the order).

We also find that those who are more altruistic are no more likely to comply with the order, suggesting that they are no more responsive to the positive externalities associated with the recommendations. The point estimates are positive and close to zero, and robust to using either underlying measure of altruism. Across all estimates, the mean lower bound of the $95 \%$ confidence interval is a reduction in noncompliance of 0.01 (i.e., a 1 standard deviation increase in altruism is associated with only a 1 percentage point reduction in non-compliance). This lack of responsiveness to primary preferences regarding uncertainty (i.e., risk preference) and consideration for others (i.e., altruism) persists even when controlling for potential correlates of preferences that also reduce the risk of COVID-19 severity (i.e., gender, age, and health status).

Similarly, those who have (or are living with those who have) health factors that increase the severity of COVID-19 are also no more likely to comply. Again, the point estimates go in the opposite direction - though statistically insignificant, those with health concerns are less likely to follow recommendations. We generally find the same pattern for each health condition separately. Across all estimates, the mean lower bound of the $95 \%$ confidence interval is a reduction in non-compliance of 0.046 (i.e., having a high risk characteristic is associated with a 4.6 percentage point 
reduction in non-compliance). The corresponding mean upper bound of the $95 \%$ confidence interval is an associated increase in non-compliance of 13.6 percentage points. Our results are consistent with the Kaiser Family Foundation polls in March, which found similar levels of social distancing, and that social distancing behaviors were no different among those who have a chronic health factor or are over the age of 60 (Hamel et al. 2020; Ashley and Brodie 2020).

One explanation is that factors correlated with pre-existing health have opposing effects on the decision to socially distance. For example, these individuals may be employed in sectors requiring social contact, or may be more reliant on extended social networks. While this is an explanation for why health factors do not predict social distancing, it still implies that policies that assume that those with greater risk factors will naturally have higher compliance with social distancing may be misguided.

Our results are robust to excluding controls (Table A1), expanding the sample to include subjects that completed only one survey instrument (Table A2), and relaxing the assumption that measures are time-invariant (Tables A3-A5).

\section{Discussion and conclusion}

We find that primary preferences and health factors fail to predict compliance with recommendations and orders on social distancing, a key strategy of the public policy response to the pandemic. Our results suggest that voluntary enforcement may not produce the expected efficiency gains from greater selective compliance by those who experience greater benefits, including by those most at risk for severe illness from COVID-19. The results also suggest that inferences of other people's preferences based on whether they socially distance may be mistaken.

Our findings with respect to risk tolerance indicate one nuance: we find that more risk tolerant individuals are more likely to leave their home and interact socially for employment or to obtain essential services (banking, food, or health care) - i.e., for purposes that were allowed under the order. In contrast, we find that risk tolerance has no predictive power when excluding permissible purposes. This indicates that within the bounds of the order, individuals are making decisions that align with their risk preferences. But in determining whether to violate the guidelines in the order, risk preferences are not relevant.

We note that our findings may be most externally valid for younger and more educated populations. In a cross-country survey, Falk et al. (2018b) find that young people tend to be more risk tolerant, and that those with higher cognitive ability tend to be more altruistic and also more risk tolerant. In general, young adults comprise a large share of the population and their behaviors meaningfully impact the larger population in the context of an infectious disease. In light of this, our results are not just informative to broad public policy, but also to university policies which generally extend to a large proportion of a local population. Across the country, universities have also had to decide how to enact and enforce their own policies on social distancing as they consider reopening their campuses to young adults.

One explanation for our findings is that uncertainty about the consequence of the pandemic may make it difficult for individuals to accurately assess their best 
response. However, recent polling suggests that information about prevention, transmission, and risk of coronavirus is well understood (Hamel et al. 2020), suggesting that lack of information about COVID-19 by itself is not a barrier. However, an individual's best response may still be unclear, and learning over time may result in people becoming increasingly responsive to COVID-19 based on their own underlying preferences and risk factors, as expected. But at least in the initial stages of a pandemic, our findings caution against policies that rely on the assumption that young adults will respond based on their true marginal benefit from doing so.

Acknowledgements We thank Justin Cook, Rowena Gray, and Jason Lee. This study was not supported by any funding sources. Analysis is motivated by a pre-analysis plan registered in the American Economic Association's Randomized Controlled Trial Registry, in which we pre-specify estimating heterogeneity by risk preferences, personal health risks, and altruism on a related intervention's effect on social distancing (AEARCTR-0005612).

\section{Compliance with ethical standards}

Conflict of interest The authors declare that they have no conflict of interest.

Publisher's note Springer Nature remains neutral with regard to jurisdictional claims in published maps and institutional affiliations.

\section{References}

Allcott, H., Boxell, L., Conway, J., Gentzkow, M., Thaler, M., \& Yang, D. Y. (2020). Polarization and public health: Partisan differences in social distancing during the Coronavirus pandemic. NBER Working Paper w26946.

Anderson, L. R., \& Mellor, J. M. (2008). Predicting health behaviors with an experimental measure of risk preference. Journal of Health Economics, 27, 1260-1274.

Barrios, J. M., \& Hochberg, Y. (2020). Risk perception through the lens of politics in the time of the COVID-19 pandemic. No. w27008. National Bureau of Economic Research.

BBC. (2020). Very selfish: Matt Hancock condemns those still socializing amid coronavirus pandemic. The Guardian. https:/www.theguardian.com/politics/video/2020/mar/23/very-selfish-matt-hancockcondemns-those-still-socialisingin-uk-video.

Behrmann, S. (2020). Fauci takes heat from protesters of stay-at-home orders, says ignoring guidelines will 'backfire'. Canton Daily Ledger. https://www.cantondailyledger.com/zz/news/20200421/fauci-takesheat-from-protesters-of-stay-at-home-orders-says-ignoring-guidelines-will-backfire?rssfeed=true.

Bish, A., \& Michie, S. (2010). Demographic and attitudinal determinants of protective behaviours during a pandemic: a review. British Journal of Health Psychology, 15, 797-824.

Bults, M., Beaujean, D. J., de Zwart, O., Kok, G., van Empelen, P., van Steenbergen, J. E., Richardus, J. H., \& Voeten, H. A. (2011). Perceived risk, anxiety, and behavioural responses of the general public during the early phase of the Influenza A (H1N1) pandemic in the Netherlands: results of three consecutive online surveys. BMC Public Health, 11, 2.

Campos-Mercade, P., Meier, A., Schneider, F., \& Wengström, E. (2020). Prosociality predicts health behaviors during the covid-19 pandemic. University of Zurich, Department of Economics, Working Paper, (346).

CDC. (2020a). Covid-19 hospitalization and death by race/ethnicity. Center for Disease Control. https:// www.cdc.gov/coronavirus/2019-ncov/covid-data/investigations-discovery/hospitalization-death-byrace-ethnicity.html.

CDC. (2020b). How to protect yourself and others. Center for Disease Control. https://www.cdc.gov/ coronavirus/2019-ncov/prevent-getting-sick/prevention.html.

Chudik, A., Pesaran, M. H., \& Rebucci, A. (2020). Voluntary and mandatory social distancing: evidence on covid-19 exposure rates from chinese provinces and selected countries. NBER Working Paper 27039. 
Cohen, A., \& Einav, L. (2003). The effects of mandatory seat belt laws on driving behavior and traffic fatalities. Review of Economics and Statistics, 85, 828-843.

Dohmen, T., Falk, A., Huffman, D., Sunde, U., Schupp, J., \& Wagner, G. G. (2011). Individual risk attitudes: measurement, determinants, and behavioral consequences. Journal of the European Economic Association, 9, 522-550.

Emerson, E., \& DeSilvia, K. (2020). Las Vegas mayor's CNN interview on COVID-19 goes viral, faces criticism. Fox 5 Vegas. https://www.fox5vegas.com/las-vegas-mayor-claims-hot-summer-will-detercoronavirus-calls-again-to-reopenstate/article_1412c86a-8675-11ea-8bdf-574e72d6e0e6.html.

Falk, A., Becker, A., Dohmen, T., Enke, B., Huffman, D., \& Sunde, U. (2018a). Global evidence on economic preferences. The Quarterly Journal of Economics, 133, 1645-1692.

Falk, A., Becker, A., Dohmen, T., Enke, B., Huffman, D., \& Sunde, U. (2018b). Global evidence on economic preferences. The Quarterly Journal of Economics, 133, 1645-1692.

Falk, A., Becker, A., Dohmen, T., Huffman, D., \& Sunde, U. (2016). The preference survey module: a validated instrument for measuring risk, time, and social preferences. IZA Discussion Paper 9674.

Fischbacher, U., \& Gachter, S. (2010). Social preferences, beliefs, and the dynamics of free riding in public goods experiments. American Economic Review, 100, 541-56.

Frey, B. S., \& Meier, S. (2004). Social comparisons and pro-social behavior: testing "conditional cooperation" in a field experiment. American Economic Review, 94, 1717-1722.

Glover, A., Heathcote, J., Krueger, D., Rios-Rull, J. V. (2020). Health versus wealth: on the distributional effects of controlling a pandemic. NBER Working Paper 27046.

Hamel, L., Lopes, L., Munana, C., Kates, J., Michaud, J., \& Brodie, M. (2020). KFF coronavirus poll: March 2020.

Hurley, J., \& Mentzakis, E. (2013). Health-related externalities: evidence from a choice experiment. Journal of Health Economics, 32, 671-681.

Ibuka, Y., Chapman, G. B., Meyers, L. A., Li, M., \& Galvani, A. P. (2010). The dynamics of risk perceptions and precautionary behavior in response to 2009 (H1N1) pandemic influenza. BMC Infectious Diseases, 10, 296.

Kirzinger, A., Kearney, A., Hamel, L., \& Brodie, M. (2020). KFF Health Tracking Poll-Late April 2020: Coronavirus, Social Distancing, and Contact Tracing. Kaiser Family Foundation.

Kolm, S.-C., \& Ythier, J. M. (Eds) (2006). Handbook of the economics of giving, altruism and reciprocity: Foundations. Vol. 1. Elsevier.

Korinek, A., \& Bethune, Z. (2020). Covid-19 infection externalities: trading off lives vs. livelihoods. NBER Working Paper 27009.

Murdoch, J. (2020). Mobile phone location data of Florida beachgoers during spring break tracked to show potential coronavirus spread. Newsweek. https://www.newsweek.com/x-mode-tectonix-coronavirusheat-map-tracking-mobile-data-covid-19-spring-break-1494663.

Rampini, A. A. (2020). Sequential lifting of COVID-19 interventions with population heterogeneity. NBER Working Paper 27063.

Schmitz, H., \& Wubker, A. (2010). What determines influenza vaccination take-up of elderly Europeans? Health Economics, 20, 1281-1297.

Tan, W., \& Bhattacharjee, R. (2020). California governor issues statewide order to 'stay at home' as coronavirus cases soar. CNBC. https://www.cnbc.com/2020/03/19/california-governor-issues-sta tewide-order-to-stay-at-home-effective-thursday-evening.html.

Williams, A. (2020). Take courage: most of us will contract coronavirus, and that's a good thing. Fox 11 News. https://wjla.com/news/armstrong-army-strong/take-courage-most-of-us-will-contract-corona virus-and-thats-a-good-thing.

Wise, T., Zbozinek, T., Michelini, G., Hagan, C. C., \& Mobbs, D. (2020). Changes in risk perception and protective behavior during the first week of the COVID-19 pandemic in the United States. 